\title{
Value of Apparent Diffusion Coefficient Values in Differentiating Malignant and Benign Breast Lesions
}

\author{
Tuğba Bostan Bozkurt, Gonca Koç, Gülten Sezgin, Canan Altay, M. Fazıl Gelal, Orhan Oyar
}

Department of Radiology, İzmir Kâtip Çelebi University Atatürk Training and Research Hospital

\begin{abstract}
Background: Magnetic resonance imaging (MRI) has become a diagnostic and problem solving method for the breast examinations in addition to conventional breast examination methods. Diffusion-weighted imaging (DWI) adds valuable information to conventional MRI.

Aims: Our aim was to show the impact of apparent diffusion coefficient (ADC) values acquired with DWI to differentiate benign and malignant breast lesions.
\end{abstract}

Study Design: Diagnostic accuracy study.

Methods: Forty-six women with 58 breast masses (35 malignant, 23 benign) were examined on a $1.5 \mathrm{~T}$ clinical MRI scanner. The morphologic characteristics of the lesions on conventional MRI sequences and contrast uptake pattern were assessed. ADC values of both lesions and normal breast parenchyma were measured. The ADC values obtained were statistically compared with the histopathologic results using Paired Samples t-Test.

Results: Multiple lesions were detected in 12 (26\%) of the patients, while only one lesion was detected in
34 (74\%). Overall, 35 lesions out of 58 were histopathologically proven to be malignant. In the dynamic contrast-enhanced series, 5 of the malignant lesions were type 1 , while 8 benign lesions revealed either type 2 or 3 time signal intensity curves ( $85 \%$ sensitivity, 56\% spesifity). Mean ADC values were significantly different in malignant vs. benign lesions. $\left(1.04 \pm 0.29 \times 10^{-3} \mathrm{~cm}^{2} / \mathrm{sec}\right.$ vs. $1.61 \pm 0.50 \times 10^{-3} \mathrm{~cm}^{2} / \mathrm{sec}$ for the malignant and benign lesions, respectively, $\mathrm{p}=0.03$ ). A cut-off value of $1.30 \times 10^{-3} \mathrm{~mm}^{2} / \mathrm{sec}$ for ADC detected with receiver operating characteristic analysis yielded $89.1 \%$ sensitivity and $100 \%$ specificity for the differentiation between benign and malignant lesions.

Conclusion: ADC values improve the diagnostic accuracy of solid breast lesions when evaluated with the conventional MRI sequences. Therefore, DWI should be incorporated to routine breast MRI protocol.

Keywords: Apparent diffusion coefficient value, breast magnetic resonance imaging, diffusion-weighted imaging
Breast cancer is the most common cancer in females worldwide and the second main cause of cancer death following lung cancer. Approximately $12 \%$ of women will experience breast cancer during their lifetime (1). Therefore, breast cancer maintains its importance as a serious public health issue. The major risk factors comprise family history, genetic predisposition caused by the presence of a BRCA1 or BRCA2 gene mutation, and previously acquired breast lesions including fibrovascular papilloma, atypical ductal and lobular hyperplasia, and ductal and lobular carcinoma in situ $(2,3)$.

Imaging is crucial to diagnose and evaluate the stage and extent of breast cancer. Therefore, three types of radiologic techniques, including mammography, ultrasonography (US) and breast magnetic resonance imaging (MRI), are implemented. As a basic breast cancer scanning method, mammography is highly available, with a short scanning time. 
It has high diagnostic accuracy, particularly in the elder age group, due to the relatively increased fatty components of breast tissue. The sensitivity ranges between $63-87 \%$ depending on the degree of breast density and age (4-6). Thus, especially in dense breast tissue, further imaging methods are applied to improve the diagnostic accuracy. At least a single scanning with US in addition to mammography has been reported to yield a substantial increase in sensitivity and specificity, particularly in dense breasts (7). The main restrictions of US are the inability to detect the microcalcifications representing ductal carcinoma in situ and the fact that it is user-dependent (8). Mammography and US may be inefficient in problem solving in terms of evaluating the real size and extent of lesions, multicentricity, differentiation of residue tumor and granulation tissue following breastconserving surgery. Therefore, in challenging cases, MRI is carried out as a complementary diagnostic tool due to its superior soft tissue resolution, and capability of multiplanar and dynamic contrast enhanced (DCE) imaging without any exposure to ionizing radiation $(9,10)$.

DCE-MRI has been a sensitive method for the lesion detection, although it yields low to moderate specificity for the discrimination of malignant vs. benign lesions (11-14). In recent years, diffusion-weighted imaging (DWI), albeit not routinely used as a part of breast MRI protocol, with the implementation of ultrafast MRI sequences contributes to the evaluation of breast lesions (15-17). The principle of the DWI is related to the Brownian movement of the water particles, which is restricted due to structure of the environment depending on the cellularity degree of the lesions $(18,19)$. The apparent diffusion coefficient (ADC) value as a quantitative measurement of diffusion has been observed by several studies to further help lesion characterization and discrimination when evaluated along with DCE-MRI (20-22).

In our current study, we aimed to show the contribution of $\mathrm{ADC}$ values in the differentiation of histopathologically proven malignant and benign breast lesions.

\section{MATERIALS AND METHODS}

\section{Patients}

Forty-six women with previously detected solid breast masses with either US or mammography were recruited for this study with permission of the local Ethics Committee. Patients provided written informed consent. All MRI examinations were acquired prior to biopsy procedure. Those patients who were either pregnant or had general contraindications for MRI, including having implanted devices (e.g. clips, pacemaker), were excluded.
Five of the locally advanced breast carcinoma lesions were diagnosed with tru-cut biopsy, while other patients with either malignant or benign lesions of the breast underwent excisional biopsy.

\section{MRI scanning}

All MRI examinations were acquired on a $1.5 \mathrm{~T}$ clinical MR scanner (Intera; Philips, Netherlands). Both breasts were scanned with a dedicated four-channel breast coil (Sense breast coils, Philips, Netherlands) in the prone position. In order to avoid probable effects of menstrual cycle on ADC values, acquisitions of the premenopausal subjects were acquired between the $7^{\text {th }}$ and $12^{\text {th }}$ days of the cycle.

Acquired sequences were as follows: Axial T1- and T2weighted fat-suppressed turbo spin echo (TSE), and axial dynamic 3D fast field echo (FFE) T1-weighted sequence before and following the administration of $0.1 \mathrm{mmol} / \mathrm{kg}$ intravenous Gadobenate dimeglumine (MultiHance; Bracco Imaging, Milan, Italy) injection. Prior to contrast material administration, using single shot echo planar imaging (SS-EPI) sequence with the $b$ values of 0 and $750 \mathrm{~mm}^{2} / \mathrm{s}$, DWI was acquired with the parameters of time to repetition/time to echo (TR/TE): 5000/62 ms; matrix: 80x128; number of excitations (NEX): 2; field of view (FOV): 190x190 mm; slice thickness: $3.5 \mathrm{~mm}$; slice gap: $0.5 \mathrm{~mm}$. DW images were obtained in 165 seconds.

\section{Lesion assessment}

The images were assessed blinded to clinical, US, and mammography findings by two radiologists (G.S, M.F.G) with 3 and 10 years of experience in breast MRI, respectively. After the generation of ADC maps, all images were sent to a commercially available workstation (EWS, Philips Medical) in order to measure ADC values and draw time signal intensity curves of the lesions. The region of interest (ROI), with the size of $10 \mathrm{~mm}^{2}$, was placed manually within the lesions avoiding the cystic-necrotic and hemorrhagic components and normal contralateral breast parenchyma trying to avoid fatty areas. The lowest $\mathrm{ADC}$ value was taken into account when different ADC values were obtained within a lesion. Since the lesions with a diameter of less than $1 \mathrm{~cm}$ are often hard to visualize on DWI, these were not included in the study.

\section{Statistical analysis}

The ADC values of malignant and benign lesions and normal breast were considered continuous dependent variables and compared using Paired Sample t-test. The sensitivity, specificity, and $p$ value were measured. $P$ value was considered statistically significant when $<0.05$. The statistical analysis was performed with a software package (Statistical Package for Social Sciences, version 15.0, SPSS Inc; Chicago, Illinois, USA). 


\section{RESULTS}

The mean age of the patients was $49.07 \pm 18.10$ years with the range from 20 to 84 years and the difference between the patients with malignant vs. benign lesions was statistically significant $(33.9 \pm 12.6$ years vs. $57.2 \pm 15.2$ years, $\mathrm{p}<0.03)$.

In 46 patients, 58 lesions were detected: 12 patients (26.08\%) had multiple lesions, while a single lesion was detected in 34 (73.9\%). Consequently, 35 lesions were histopathologically diagnosed as malignant: invasive ductal carcinoma $(\mathrm{n}=19)$, invasive lobular carcinoma $(\mathrm{n}=4)$, apocrine carcinoma $(\mathrm{n}=2)$, invasive papillary carcinoma $(\mathrm{n}=2)$, medullar carcinoma $(n=3)$, malignant epithelial tumor $(n=1)$, metaplastic carcinoma $(\mathrm{n}=1)$, invasive ductal and invasive lobular carcinoma $(\mathrm{n}=1)$, invasive ductal and micropapillary carcinoma $(\mathrm{n}=1)$, and invasive ductal and invasive cribriform carcinoma $(\mathrm{n}=1)$. Overall, 23 lesions were proven to be benign: Fibroadenoma $(n=18)$, hamartoma $(n=1)$, fibrocystic change $(n=3)$, and fat necrosis $(\mathrm{n}=1)$. The lesion size ranged from $15.3 \mathrm{~mm}$ to 83.5 $\mathrm{mm}$ (mean size $36.4 \pm 18.0 \mathrm{~mm}$ ). Malignant breast lesions were larger than benign ones (mean size $41.4 \pm 12.0 \mathrm{~mm}$ vs. $18.7 \pm 9.0 \mathrm{~mm}$, respectively, $\mathrm{p}<0.001)$.

The time signal intensity curves of the breast lesions obtained from dynamic series were as follows: type 3 (wash out) was detected in $23(65.7 \%)$, while $5(14.2 \%)$ and $7(20 \%)$ of the malignant lesions revealed type 1 (steadily increasing signal intensity) and type 2 (plateau) time signal intensity curves. Overall, 13, 4, and 6 of the benign lesions had type 1, 2, and 3 time signal intensity curves, respectively. If the type 1 time course is considered to be associated with benign lesions, the shape of time signal intensity curve was found to have $85 \%$ sensitivity and $56 \%$ specificity to detect malignant lesions.

The mean ADC values of 35 malignant lesions were significantly different from that of 28 benign lesions $\left(1.04 \pm 0.29 \times 10^{-3}\right.$ $\mathrm{mm}^{2} / \mathrm{s}$, range $0.75-1.32 \times 10^{-3} \mathrm{~mm}^{2} / \mathrm{s} ; 1.61 \pm 0.50 \times 10^{-3} \mathrm{~mm}^{2} / \mathrm{s}$, range $1.11-2.11 \times 10^{-3} \mathrm{~mm}^{2} / \mathrm{s}$, respectively, $\mathrm{p}=0.03$ ) and normal breast parenchyma (mean $1.92 \pm 0.52 \times 10^{-3} \mathrm{~mm}^{2} / \mathrm{s}$, range $\left.1.05-2.44 \times 10^{-3} \mathrm{~mm}^{2} / \mathrm{s}, \mathrm{p}<0.03\right)$. The cut-off value of $1.30 \times 10^{-3}$ $\mathrm{mm}^{2} / \mathrm{s}$ detected by the peak of the receiver operating characteristic curve yielded $89.1 \%$ sensitivity and $100 \%$ specificity for the discrimination of malignant lesions from benign (Figure 1). There was no statistically significant difference between the mean ADC values of benign lesions and normal breast parenchyma $(\mathrm{p}=0.134)$.

\section{DISCUSSION}

This study evaluates the ADC values of solid breast lesions obtained prior to biopsy procedure and the results indicate a

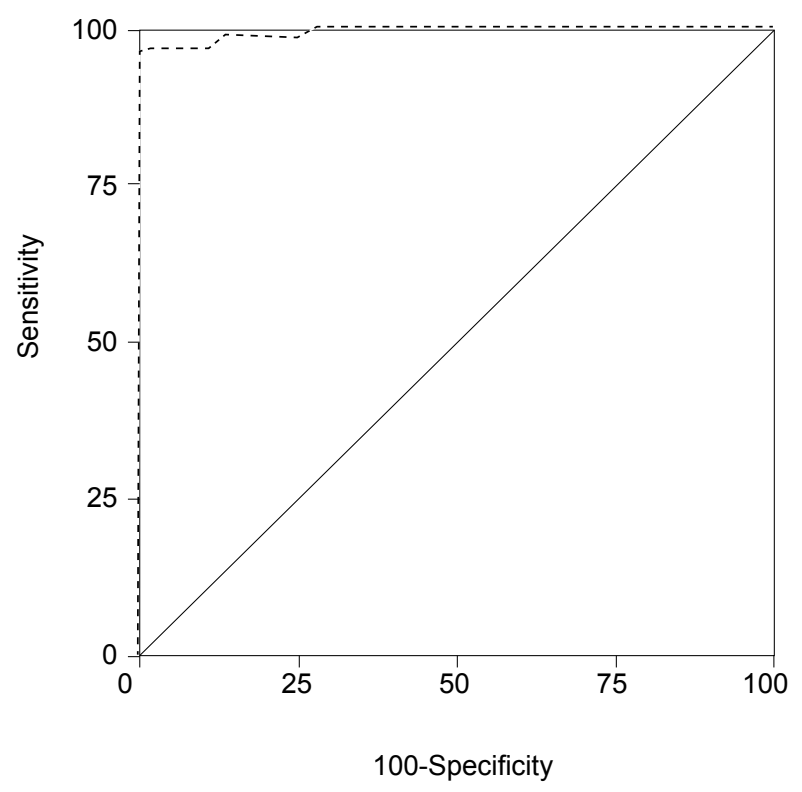

FIG. 1. The ROC analysis of the ADC values. High sensitivity and specificity can be observed

significant difference between malignant and benign lesions. A threshold ADC value of $1.30 \times 10^{-3} \mathrm{~mm}^{2} / \mathrm{s}$ in the study is compatible with the range of $1.1-1.60 \times 10^{-3} \mathrm{~mm}^{2} / \mathrm{s}$, which has been reported in the literature and helps to distinguish benign vs malignant lesions with $89.1 \%$ sensitivity and $100 \%$ specificity $(15,22-26)$.

Several studies that evaluated breast lesions using DWI have reported a range of mean $\mathrm{ADC}$ values of malignant breast lesions between $0.87 \pm 0.23$ and $1.22 \pm 0.31 \times 10^{-3} \mathrm{~mm}^{2} / \mathrm{s}$, so that the mean ADC value of malignant lesions in the current study $\left(1.04 \pm 0.29 \times 10^{-3} \mathrm{~mm}^{2} / \mathrm{s}\right)$ was in the reported range (22-26). The highest $\mathrm{ADC}$ value of malignant breast lesions was revealed by micropapillary carcinoma $\left(1.32 \pm 0.13 \times 10^{-3} \mathrm{~mm}^{2} / \mathrm{s}\right)$, while invasive ductal and cribriform carcinoma had the lowest $\left(0.78 \pm 0.24 \times 10^{-3} \mathrm{~mm}^{2} / \mathrm{s}\right)$. Since micropapillary carcinoma is histopathologically defined as the reproduction of tumor cell batches within blank stromal spaces, the relatively increased ADC value compared to invasive carcinomas may be related with randomly moving water molecules within that interstitium (27).

The range of ADC values of malignant and benign lesions mildly overlapped in accordance with the literature: 3 out of 18 fibroadenomas, which were subsequently diagnosed histopathologically, showed a relatively decreased mean ADC value of $1.16 \pm 0.13 \times 10^{-3} \mathrm{~mm}^{2} / \mathrm{s}$. The possible reason for the low ADC in fibroadenomas has been reported as predominance of the fibrous component $(28,29)$.

The ADC values were shown to better correlate with malignancy compared to time signal intensity curves, which revealed 
$85 \%$ sensitivity, and $56 \%$ specificity to detect malignant lesions. In the literature, a wide range of sensitivity (56-83\%) and specificity (46-91\%) rates of either type 2 or type 3 time signal intensity curves for the detection of malignant breast lesions have been reported (30,31). Because of this overlap in enhancement characteristics of benign and malignant breast lesions, not only reliance on kinetics assessment but combination with morphologic assessment and DWI findings is recommended.
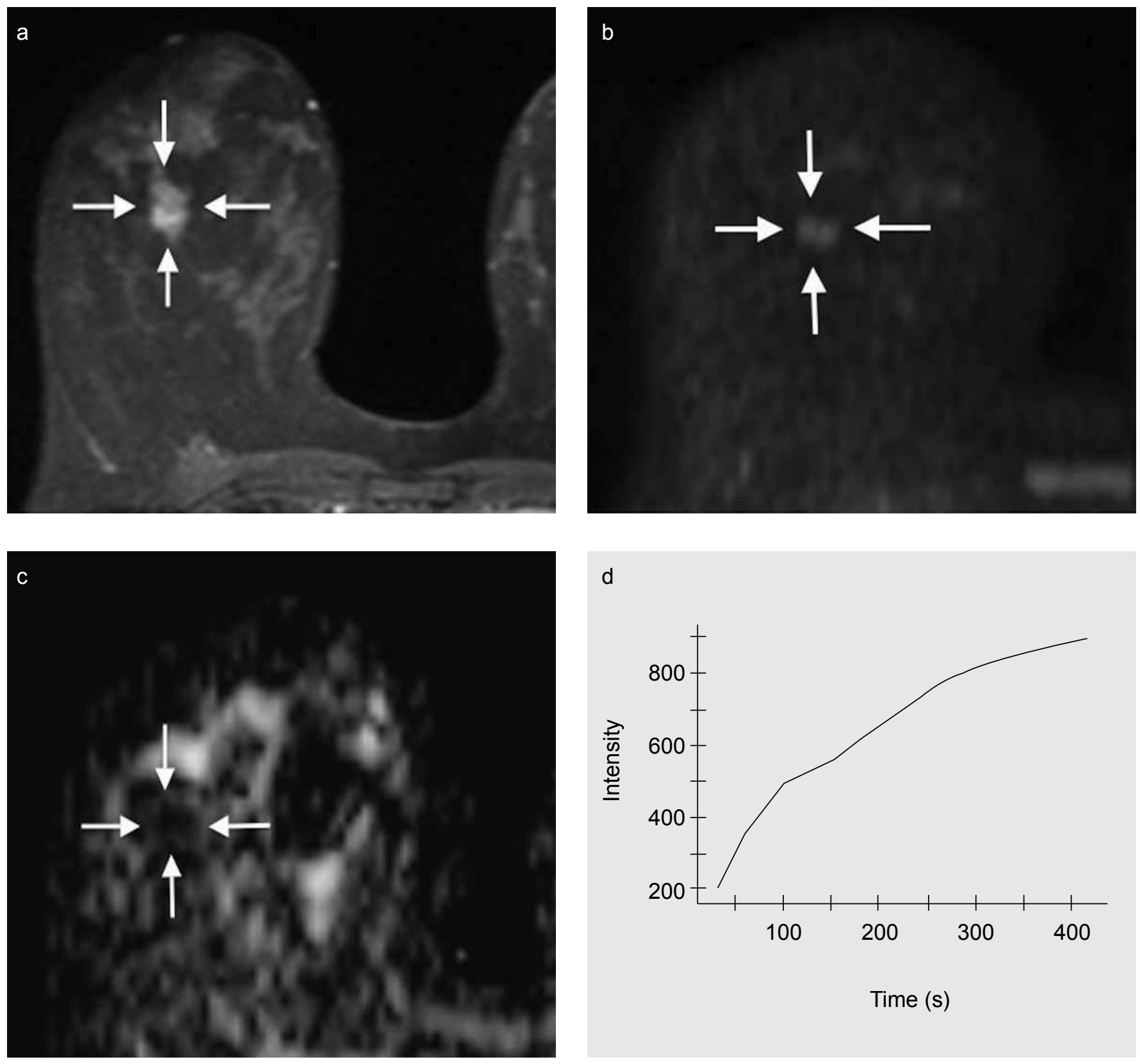

FIG. 2. a-d. A 55 year-old female with medullary carcinoma. T1 weighted fat saturated axial image acquired after contrast media administration revealed a strongly enhancing breast lesion with macrolobulated margins (arrows) (a). The lesion had diffusion restriction that was seen as hyperintense on DWI image (arrows) (b) and hypointense on ADC map (arrows) (c). Mean ADC value: $1.13 \times 10^{-3} \mathrm{~mm}^{2} / \mathrm{s}$. A type 1 time signal intensity curve was detected $(\mathrm{d})$. 
a lesser degree than other malignant breast tumors $(29,32)$. Besides, some benign breast lesions may imitate malignant lesions in terms of contrast uptake pattern due to proliferative activities of hyperplastic parenchymal cells (28). Particularly in the acute period of fat necrosis, proliferative dysplasia, and myxoid fibroadenoma, scar tissue formed very fast following surgical procedures (within first 6 months) and radiotherapy (within first 18 months) and vivid contrast uptake in the early period may be observed $(32,33)$. In concordance with the literature, 5 ma-
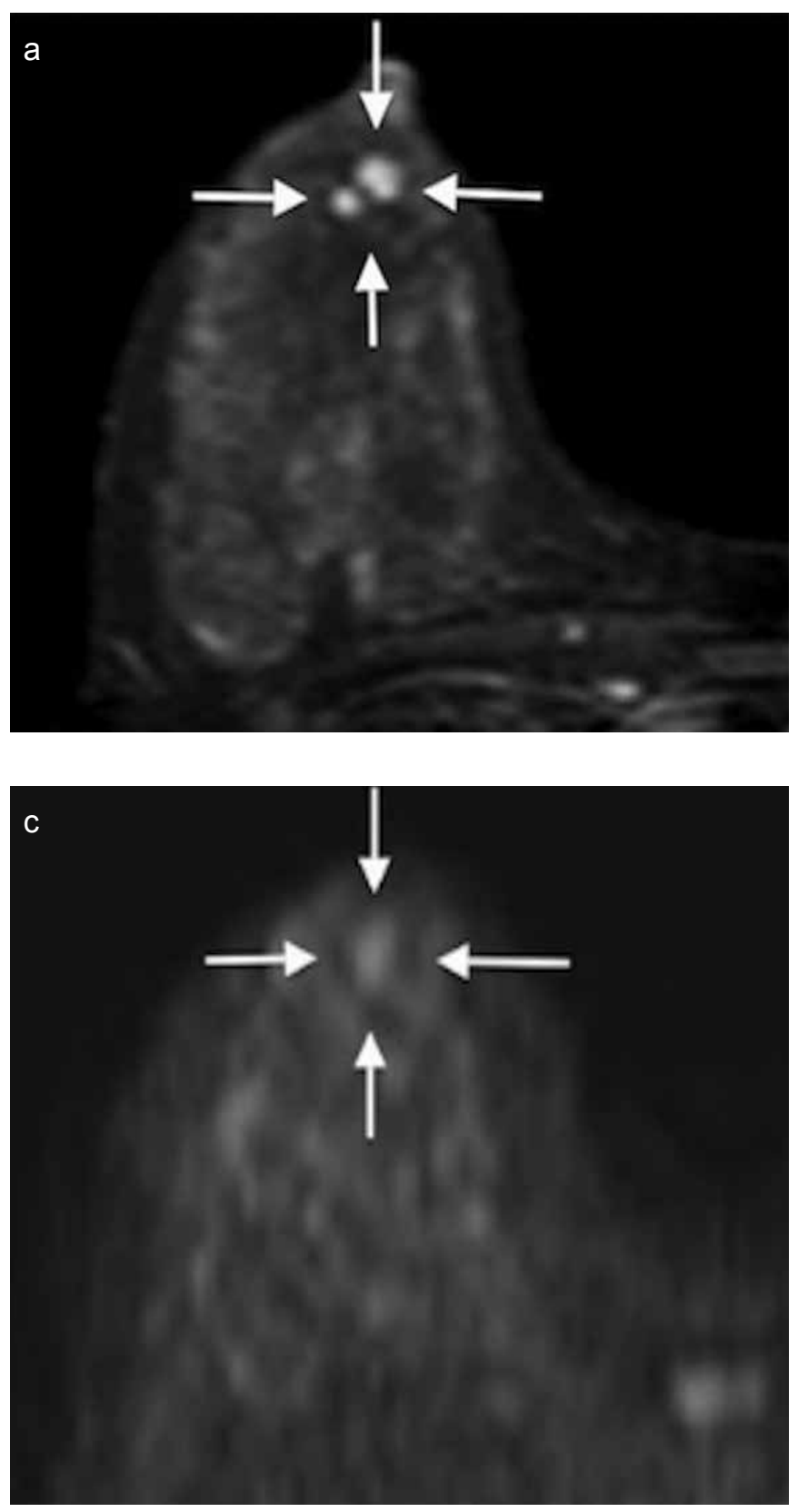

lignant lesions of 35 , including 2 of the medullary carcinoma, invasive mixed carcinoma, metaplastic carcinoma, and invasive lobular carcinoma revealed type 1 time signal intensity curve, as well as 5 of the fibroadenomas and one lesion of fat necrosis, were found to have type 3 curves (Figure 2, 3).

As shown in our current study, DWI holds promise to improve the diagnostic performance of DCE-MRI (34). The decreased levels of ADC values of malignant tumors reflect the biological characteristics of tumor, such as cellularity and wa-
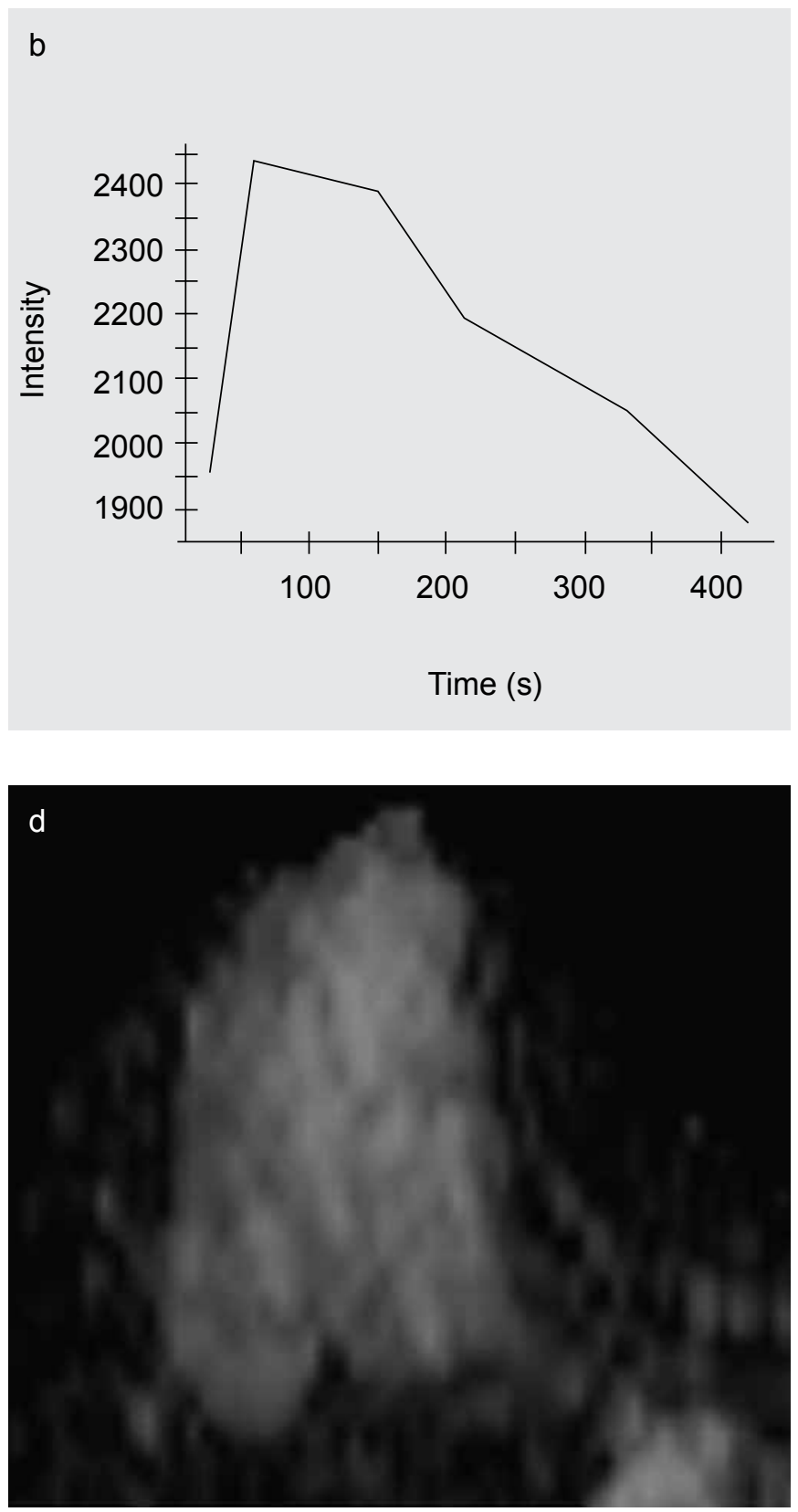

FIG. 3. a-d. A 28 year-old female with histopathologically proven fibroadenoma. On contrast enhanced T1 weighted axial fat saturated image, an enhancing lesion was seen (arrows) (a). Despite the type 3 time signal intensity curve drawn within the lesion (b) no diffusion restriction was revealed on diffusion-weighted image (arrows) (c) and ADC map (d). Mean ADC value: $1.65 \times 10^{-3} \mathrm{~mm}^{2} / \mathrm{s}$. 
ter content. Malignant tumors consisted of intensely packed and randomly organized tumor cells interfere the effective movement and restrict diffusion of water particles. Conversely, higher ADC values are usually associated with well-differentiated tumors or benign conditions. In keeping with our findings, in previous studies, lower ADC values were reported to be associated with malignant breast tumors rather than benign conditions $(35,36)$. Constantini et al. (37) reported an inverse correlation between the tumor grade and ADC values.

When obtaining DWI, the selection of $b$ value is of great importance. At $b$ values of $400 \mathrm{~s} / \mathrm{mm}^{2}$ and below, the ADC value is affected with the diffusion of water as well as the microcirculation of blood located in the capillary bed of tissues and perfusion (27). As a consequence, lower b values result in higher ADC values. Although no consensus exists on the appropriate $b$ value, Pereira et al. (26) compared the ADC values of malign breast tumors acquired at various $b$ values and reported the ADC values at $750 \mathrm{~mm}^{2} / \mathrm{s}$ to be more sensitive than lower ones for the estimation of malignant potential (19). Similarly, as the preferred b value at our institution, $750 \mathrm{~mm}^{2} / \mathrm{s}$ was implemented. Since the higher $b$ value means a lower signal to noise ratio, the optimization of DWI with appropriate $b$ value is essential without a significant compromise on resolution.

The study has several limitations to be considered. Since breast lesions with the diameter of less than $1 \mathrm{~cm}$ are hard to visualize with DWI and may exhibit incorrect ADC values, those lesions previously detected with either US or mammography were not included in our study (27). Therefore, DWI has to be an adjunct technique to conventional sequences and DCE-MRI for the detection and assessment of breast lesions of various sizes. Since prolonged acquisition time may lead to misalignment artifacts caused by patient motion, we utilized a combined $b$ value of 0 and $750 \mathrm{~mm}^{2} / \mathrm{s}$. However, whether the selection of $b$ values would influence ADC measurements acquired from breast lesions is controversial $(26,38)$. Thus, the optimum ADC value, reducing T2 shine through and perfusion effect while maintaining resolution, should be investigated with further clinical studies.

In conclusion, DWI, as used worldwide in other fields of diagnostic imaging, is a promising method in breast imaging. Although it is not routinely included in breast MRI protocol, the implementation of DWI is simple, without any significant time compromise. Furthermore, quantification of the method using ADC value measurements may help to more accurately predict the malignant potential of breast lesions prior to histopathological sampling.

Ethics Committee Approval: Ethics committee approval was obtained for this study from the ethics committee of Ataturk Teaching and Research Hospital Local Ethical Committee (Date: 30 April 2009, Meeting number: 2009/597).
Informed Consent: Written informed consent was obtained from the patients who participated in this study.

Peer-review: Externally peer-reviewed.

Author contributions: Concept - T.B.B., G.S., M.F.G.; Design - T.B.B, G.K., C.A.; Supervision - M.F.G., O.O.; Resource - G.S., C.A., O.O.; Materials - G.K., T.B.B., C.A.; Data Collection and/or Processing - T.B.B., M.F.G., C.A.; Analysis and/or Interpretation T.B.B., G.K., G.S.; Literature Search - G.K., T.B.B.; Writing - G.K., T.B.B., C.A.; Critical Reviews - M.F.G, O.O.

Conflict of Interest: No conflict of interest was declared by the authors.

Financial Disclosure: The authors declared that this study has received no financial support.

\section{REFERENCES}

1. Sasieni PD, Shelton J, Ormiston-Smith N, Thomson CS, Silcocks PB. What is the lifetime risk of developing cancer? The effect of adjusting for multiple primaries. Br J Cancer 2011;105:460-5. [CrossRef]

2. Malone KE, Daling JR, Thompson JD, O'Brien CA, Francisco LV, Ostrander EA. BRCA1 mutations and breast cancer in the general population: analyses in women before age 35 years and in women before age 45 years with first-degree family history. JAMA 1998;279:922-9. [CrossRef]

3. Soerjomataram I, Louwman WJ, van der Sangen MJC, Roumen RM, Coebergh JW. Increased risk of second malignancies after in situ breast carcinoma in a population based registry. Br J Cancer 2006; 95:393-97. [CrossRef]

4. Carney PA, Miglioretti DL, Yankaskas BC, Kerlikowske K, Rosenberg R, Rutter CM et al. Individual and combined effects of age, breast density, and hormone replacement therapy use on the accuracy of screening mammography. Ann Intern Med 2003;138:168-75. [CrossRef]

5. Rosenberg RD, Hunt WC, Williamson MR, Gilliland FD, Wiest PW, Kelsey CA et al. Effects of age, breast density, ethnicity, and estrogen replacement therapy on screening mammographic sensitivity and cancer stage at diagnosis: review of 183,134 screening mammograms in Albuquerque, New Mexico. Radiology 1998;209:511-8. [CrossRef]

6. Kerlikowske K, Grady D, Barclay J, Sickles EA, Ernster V. Likelihood ratios for modern screening mammography. Risk of breast cancer based on age and mammographic interpretation. JAMA 1996;276:39-43. [CrossRef]

7. Wendie A. Berg, Jeffrey D. Blume, Jean B. Cormack, Ellen B. Mendelson, Daniel Lehrer, Marcela Böhm-Vélez et al. Combined screening with ultrasound and mammography vs mammography alone in women at elevated risk of breast cancer. JAMA 2008;299:2151-63. [CrossRef]

8. Kolb TM, Lichy J, Newhouse JH. Comparison of the performance of screening mammography, physical examination and breast US 
and evaluation of factors that influence them: an analysis of 27.825 patient evaluations. Radiolgy 2002;225:165-75. [CrossRef]

9. Rankin C. MRI of the breast. Br J Radiol 2000;73:806-18. [CrossRef]

10. Lee CH. Problem solving MR imaging of the breast. Radiol Clin North Am 2004; 42:919-34. [CrossRef]

11. Macura KJ, Ouwerkerk R, Jacobs MA, Bluemke DA. Patterns of enhancement on breast MR images: interpretation and imaging pitfalls. Radiographics 2006;26:1719-34. [CrossRef]

12. Fischer U, Kopka L, Grabbe E. Breast carcinoma: effect of preoperative contrast-enhanced MR imaging on the therapeutic approach. Radiology 1999;213:881-8. [CrossRef]

13. Kul S, Cansu A, Alhan E, Dinc H, Reis A, Can G. Contrast-enhanced MR angiography of the breast: evaluation of ipsilateral increased vascularity and adjacent vessel sign in the characterization of breast lesions. AJR Am J Roentgenol 2010; 95:1250-4. [CrossRef]

14. Szabo BK, Aspelin P, Wiberg MK, Bone' B. Dynamic MR imaging of the breast analysis of kinetic and morphologic diagnostic criteria. Acta Radiol 2003;44:379-86. [CrossRef]

15. Hatakenaka M, Soeda H, Yabuuchi H, Matsuo Y, Kamitani T, Oda $Y$ et al. Apparent diffusion coefficients of breast tumors: clinical application. Magn Reson Med Sci 2008;7:23-9. [CrossRef]

16. Park MJ, Cha ES, Kang BJ, Ihn YK, Baik JH. The role of diffusionweighted imaging and the apparent diffusion coefficient (ADC) values for breast tumors. Korean J Radiol 2007;8:390-6. [CrossRef]

17. Wenkel E, Geppert C, Schulz-Wendtland R, Uder M, Kiefer B, Bautz W et al. Diffusion weighted imaging in breast MRI: comparison of two different pulse sequences. Acad Radiol 2007;14:1077-83. [CrossRef]

18. Bydder G.M, Rutherford M.A, Hajnal J.V. How to perform diffusionweighted imaging. Child's Nerv Syst 2001:195-201. [CrossRef]

19. Bammer R. Basic principles of diffusion-weighted imaging. European Journal of Radiology 2003; 45:169-84. [CrossRef]

20. Yoshikawa MI, Ohsumi S, Sugata S, Kataoka M, Takashima S, Kikuchi $\mathrm{K}$ et al. Comparison of breast cancer detection by diffusion-weighted magnetic resonance imaging and mammography. Radiat Med 2007;25:218-23. [CrossRef]

21. Kuroki-Suzuki S, Kuroki Y, Nasu K, Nawano S, Moriyama N, Okazaki M. Detecting breast cancer with non-contrast MR imaging: combining diffusion-weighted and STIR imaging. Magn Reson Med Sci 2007;6:21-7. [CrossRef]

22. Marini C, Lacconi C, Giannelli M, Cilotti A, Moretti M, Bartolozzi C. Quantitative diffusion-weighted MR imaging in the differential diagnosis of breast lesion. Eur Radiol 2007; 17:264655. [CrossRef]

23. Guo Y, Cai YQ, Cai ZL, Gao YG, An NY, Ma L. Differentiation of clinically benign and malignant breast lesions using diffusion-weighted imaging. J Magn Reson Imaging 2002;16:172-8. [CrossRef]

24. Woodhams R, Matsunaga K, Kan S, Hata H, Ozaki M, Iwabuchi $\mathrm{K}$. ADC mapping of benign and malignant breast tumors. Mag Res Med Sci 2005;4:35-42. [CrossRef]

25. Luo JD, Liu YY, Zhang XL, Shi LC. Application of diffusion weighted resonance imaging to differential diagnosis of breast diseases. Ai Zheng 2007;26:168-71. Chinese.
26. Pereira FP, Martins G, Figueiredo E, Domingues MN, Domingues $\mathrm{RC}$, da Fonseca LM et al. Assessment of breast lesions with diffusion-weighted MRI: comparing the use of different $\mathrm{b}$ values. $A J R$ Am J Roentgenol 2009;193:1030-5. [CrossRef]

27. Kinoshita T, Yashiro N, Ihara N, Funatu H, Fukuma E, Narita M. Diffusion-weighted half-Fourier single-shot turbo spin echo imaging in breast tumors: differentiation of invasive ductal carcinoma from fibroadenoma. J Comput Assist Tomogr 2002;26:1042-6. [CrossRef]

28. Bone B, Wiberg MK, Parrado C, Falkmer U, Aspelin P, Gad A. Mechanism of contrast enhancement in breast lesions at MR imaging. Acta Radiol 1998;39:494-500. [CrossRef]

29. Reimer P, Parizel PM, Stichnoth FA. A practical approach clinical MR imaging. IN: Khul C, ed. Magnetic resonanace of breast. 1 st ed. Berlin: Springer. 1999;397-414.

30. Kuhl CK, Mielcareck P, Klaschik S, Leutner C, Wardelmann $\mathrm{E}$, Gieseke J. Dynamic breast MR imaging: is signal intensity time course data useful for differential diagnosis of enhancing lesions? Radiology 1999;211:101-10. [CrossRef]

31. El Khouli RH, Macura KJ, Jacobs MA, Khalil TH, Kamel IR, Dwyer A. Dynamic contrast-enhanced MRI of the breast: quantitative method for kinetic curve type assessment. AJR Am J Roentgenol 2009;193:295-300. [CrossRef]

32. Gilles R, Guinebretiere JM, Lucidarme O, Cluzel P, Janaud G, Finet JF et al. Nonpalpable breast tumors: diagnosis with contrast-enhanced subtraction dynamic MR imaging. Radiology 1994;191:625-31. [CrossRef]

33. Ducatman BS, Emery ST, Wang HH. Correlation of histologic grade of breast carcinoma with cytologic features on fine-needle aspiration of the breast. Mod Pathol 1993;6:539-43.

34. Partridge SC, DeMartini WB, Kurland BF, Eby PR, White SW, Lehman CD. Quantitative diffusion-weighted imaging as an adjunct to conventional breast MRI for improved positive predictive value. AJR Am J Roentgenol 2009;193:1716-22. [CrossRef]

35. Yabuuchi H, Matsuo Y, Okafuji T, Kamitani T, Soeda H, Setoguchi $\mathrm{T}$ et al. Enhanced mass on contrast-enhanced breast MR imaging: Lesion characterization using combination of dynamic contrast-enhanced and diffusion- weighted MR images. J Magn Reson Imaging 2008;28:1157-65. [CrossRef]

36. Baltzer PA, Benndorf M, Dietzel M, Gajda M, Camara O, Kaiser WA. Sensitivity and specificity of unenhanced MR mammography (DWI combined with T2-weighted TSE imaging, ueMRM) for the differentiation of mass lesions. Eur Radiol 2010;20:110110. [CrossRef]

37. Costantini M, Belli P, Rinaldi P, Bufi E, Giardina G, Franceschini $G$ et al. Diffusion-weighted imaging in breast cancer: relationship between apparent diffusion coefficient and tumour aggressiveness. Clin Radiol 2010;65:1005-12. [CrossRef]

38. Peters NH, Vinvken KL, van den Bosch MA, Luijten PR, Mali WP, Bartels LW. Quantitative diffusion weighted imaging for differentiation of benign and malignant breast lesions. The influence of the choice of-b values. J Magn Reson Imaging 2010;31:1100-05. [CrossRef] 